\title{
Aplicação de um modelo matemático para estudar a qualidade de água do rio Piranhas-Açu/RN tomando como referência os parâmetros DBO e coliformes termotolerantes
}

\author{
Application of a mathematical model to study the water quality of \\ the river Piranhas- $A c ̧ u / R N$ reference to the DBO parameters and \\ fecal coliforms
}

\author{
Roani Simões Veras \\ roaniveras30@gmail.com \\ Universidade de Fortaleza \\ Ingrid Fernandes de \\ Oliveira Alencar \\ ingrid.foa@hotmail.com \\ Universidade de Fortaleza \\ Victor Prisco Diogo de \\ Holanda \\ victor_prisco@hotmail.com \\ Universidade de Fortaleza \\ Thainá Rayanne Soares \\ thainasoares90@gmail.com \\ Universidade de Fortaleza \\ Raquel Jucá de Moraes \\ Sales \\ raqueljuca@gmail.com \\ Universidade de Fortaleza
}

\begin{abstract}
Resumo
$\mathrm{Na}$ intenção de encontrar mecanismos que auxiliem no diagnóstico da qualidade de água de rios naturais de forma prática, esta pesquisa trata da análise dos parâmetros DBO e coliformes termotolerantes, utilizando o modelo de Streeter-Phelps simplificado, com base em um estudo de caso do rio Piranhas-Açu, Rio Grande do Norte. Pelos resultados, verificou-se que, para maiores vazões do rio e menores concentrações dos efluentes, os corpos d'água conseguem diluir as cargas poluentes de forma mais eficiente, permitindo maiores possibilidades de lançamento segundo a legislação vigente, como previsto em literatura. Observou-se ainda que, para períodos de estiagem, o monitoramento desses recursos hídricos deve ser realizado de forma mais rigorosa, já que há uma maior probabilidade da presença de poluentes em altas concentrações. Com este estudo, pode-se estabelecer, de forma simples, critérios de avaliação da qualidade da água, facilitando a tomada de decisão por parte de gestores ambientais.
\end{abstract}

Palavras-chave: Demanda bioquímica de oxigênio. Coliformes termotolerantes. Qualidade de água. Streeter-Phelps.

\begin{abstract}
In an attempt to find mechanisms that assist in quality diagnosis of water from natural rivers in a practical way, this research deals with the analysis of BOD and fecal coliform parameters, using the Streeter-Phelps simplified model based on one case study of the river Piranhas-Açu, Rio Grande do Norte. From the results, it was found that for higher flows of the river and lower concentrations of the effluents, the water bodies can dilute the pollutant loads more efficiently, allowing greater release of possibilities under the current legislation, as provided in literature. It was also observed that in periods of drought, the monitoring of these water resources should be carried out more rigorously, as there is an increased likelihood of the presence of pollutants in high concentrations. This study can help establish in a simple way the criteria for assessing water quality, facilitating decision-making on the part of environmental managers.
\end{abstract}

Keywords: Biochemical Oxygen Demand. Thermotolerant Coliforms. Water quality. StreeterPhelps.

\section{Considerações iniciais}

O crescimento populacional desordenado nos grandes centros urbanos está relacionado ao aumento da demanda de água, à elevação do desperdício em redes de distribuição e de consumo doméstico e à intensificação da contaminação dos corpos hídricos, evidenciando a necessidade do uso racional da água, devido à sua incontestável importância, além de ser um bem comum natural limitado e um recurso que se encontra em desigual distribuição nas diversas regiões do planeta.

Sabe-se que o decréscimo da quantidade disponível dos recursos hídricos ocorre principalmente por motivo do consumo irresponsável e pela poluição dos meios aquáticos. Consequentemente, as temáticas relacionadas à gestão 
ambiental do uso da água e ao desenvolvimento sustentável estão constantemente sendo debatidas com pertinentes preocupações pelos aspectos sociais, econômicos e políticos; porém, já é notória a redução do volume de água potável para consumo humano. Cândido e Santos (2000) advertem que há, a cada dia, uma crescente diminuição da quantidade de água potável disponível.

A poluição hídrica se baseia nas atividades antrópicas que podem causar prejuízo ao homem ou a outras formas de vida, assim, Chagas (2005) sustenta a ideia de que as características da água podem ser alteradas por substâncias como compostos orgânicos, micro-organismos patogênicos, metais pesados, entre outras que estão presentes nos efluentes e são provenientes de tais atividades. Essa poluição acarreta efeitos danosos à sociedade, como: elevação de gastos com tratamento dos recursos hídricos, comprometimento de seu uso para diferentes finalidades e complicações relacionadas à escassez da água. Macris (2000) afirma que o Poder Público passou a atentar mais vigorosamente para os problemas do uso irracional dos recursos hídricos. Para o autor, as leis são instrumentos de grande importância no auxílio de uma gestão ambiental eficaz e o Estado deve adotá-las de forma sustentável a fim de assegurar o acesso da população à água de boa qualidade.

Com o objetivo de realizar uma gestão mais eficiente dos recursos hídricos, a Política Nacional de Recursos Hídricos, instituída pela Lei n ${ }^{\circ}$ 9.433/97, criou o Plano Nacional de Recursos Hídricos (PNRH) e o Conselho Nacional do Meio Ambiente (CONAMA), que, por meio da resolução $\mathrm{n}^{\circ} 357 / 2005$, estabelece diretrizes para o enquadramento dos corpos de água em diferentes classes, no que se refere às condições e padrões de lançamento de efluentes. Para cada classe dos recursos hídricos são determinados limites de concentrações de poluentes com o objetivo de manter ou melhorar a qualidade da água.

A outorga dos direitos de uso dos recursos hídricos é um dos instrumentos que apoiam a implementação da Política Nacional de Recursos Hídricos. Segundo Melo (2006), outorga é uma concessão autorizada por órgãos responsáveis pelo direito de captação, lançamento de efluentes ou outras atividades que alterem as características de um corpo d'água. Cruz (2001) argumenta que a outorga visa manter a qualidade de um curso de água, em conformidade com seu uso final, após o lançamento e os processos de dispersão dos poluentes. Azevedo et al. (2003) mencionam que a outorga para a diluição do lançamento de efluentes nos corpos receptores é um dos principais instrumentos de controle da poluição hídrica, porém não está implantada em todo o território nacional. Os autores acrescentam que para a exploração dessa área de controle são necessários critérios de outorga que mantenham sistemas com bases de dados que levem em consideração a situação dos recursos hídricos.

Modelos matemáticos são desenvolvidos para otimizar métodos de gerenciamento de recursos hídricos incorporando os sistemas que ocorrem nos rios de maneira funcional, para previsão de impactos e ações corretivas ao meio aquático. Suas aplicações requerem dados precisos adquiridos por fiscalização e monitoramento para que haja retornos reais das situações analisadas.

De acordo com Li et al. (2007) e Chandra et al. (2009), muitas incertezas devem ser analisadas na formulação de um modelo de qualidade de água, como: a variabilidade do fluxo de transporte de poluentes, os processos físico-químicos, o tempo de transmissão, as interações dinâmicas entre cargas de poluentes e corpos de água receptores, a indeterminação da água disponível e esgoto tratado, e a natureza aleatória dos processos meteorológicos e condições hidrodinâmicas. Fitzpatrick (2009) afirma que as limitações de dados irão influenciar na entrada de dados e, consequentemente, no grau de retorno do modelo.

Cox (2003) evidencia que um modelo matemático pode ser de grande utilidade para normatização da legislação e otimização de recursos, independentemente de complexidades para a implantação dessa ferramenta. Bezerra et. al. (2008) admitem que utilizar modelos matemáticos proporciona não só uma melhoria no controle de qualidade dos recursos hídricos, como uma prevenção nos impactos ambientais de futuros projetos.

Muitos modelos matemáticos que analisam a qualidade das águas são baseados no modelo de Streeter-Phelps. Esse modelo apresenta conceitos de fácil entendimento para sua aplicação, uma vez que são utilizados dados simples de entrada, contribuindo para sua utilização em diversas situações.

Diversos estudos foram e estão sendo desenvolvidos com base em modelos matemáticos para o entendimento de como se comporta a disponibilidade de oxigênio dissolvido em meio à atuação de uma fonte poluente. $\mathrm{O}$ modelo dos autores Streeter e Phelps (1925), desenvolvido para o rio Ohio nos Estados Unidos, serviu de base para muitos modelos que utilizamos atualmente. Segundo Sperling (2007), devido à facilidade dos conceitos envolvidos e da simples necessidade de entrada de dados, é comum que as simulações de oxigênio dissolvido sejam realizadas por meio desse modelo no 
Brasil. Mannina e Viviani (2010) analisam que todos os processos biológicos e físico-químicos mais significativos são contemplados por tal modelo. Conforme Sales et. al. (2014), as equações de Streeter-Phelps são equações lineares, o que possibilita a inserção de soluções por superposição. Assim sendo, podem-se adicionar processos indefinidamente. Melo (2006) concluiu, a partir dos resultados obtidos na realização de um trabalho acadêmico, que o modelo de Streeter-Phelps deve ser empregado na metodologia das análises de lançamento de efluentes, pois quando aplicado aos conceitos de autodepuração aproxima os corpos d'água às condições reais.

O aumento da população mundial e o crescimento do consumo de bens e serviços geram grandes quantidades de rejeitos de diferentes origens. Para Silveira e Teles (2006), essa crescente necessidade por recursos naturais ocasiona a produção de resíduos líquidos que em sua maioria são depositados em corpos d'água sem o tratamento necessário, ocasionando possíveis modificações hídricas. Braga et al. (2005) definem autodepuração como um processo natural de recuperação de um rio que tenha sofrido algum processo de poluição. Os autores ressaltam que esse processo é realizado por meio de mecanismos físicos, químicos e biológicos, em que compostos recalcitrantes e inorgânicos não participam desse recurso de recuperação do equilíbrio ecológico. Andrade (2010) comenta que o mecanismo de autodepuração pode apresentar melhorias na qualidade da água dependendo do nível de poluição do rio. Chagas (2005) cita os principais fenômenos que participam da autodepuração dos rios como sendo: fenômenos físicos, nos quais se apresentam a capacidade de diluição inicial, a turbulência da água, a sedimentação, a variação da temperatura e a presença de luz solar; fenômenos químicos, representados pelas reações de oxidação e redução; e fenômenos biológicos, em que são citados o predatismo, a aglutinação e a produção de antibióticos e toxinas.

$\mathrm{Na}$ gestão da qualidade da água, são utilizados parâmetros como demanda bioquímica de oxigênio (DBO) e coliformes termotolerantes (CTT), entre outros. Esses parâmetros são de fundamental importância na avaliação das condições ambientais do meio aquático, o que favorecerá as condições da saúde pública de uma determinada região.

De acordo com Boano et. al. (2006), os efluentes oriundos de processos industriais e de uso doméstico apresentam comumente produtos contaminados por substâncias biodegradáveis. Andrade (2010) define DBO como a quantidade de oxigênio necessária para que os micro-organismos aeróbios decomponham a matéria orgânica. Portanto, continua o autor, a demanda bioquímica de oxigênio não deve ser considerada um poluente, e sim, um parâmetro que indica o consumo de oxigênio no processo de estabilização do corpo hídrico.

Os micro-organismos são extremamente importantes no desenvolvimento do processo de decomposição da matéria orgânica e, consequentemente, na redução da DBO nos rios. Entretanto, ressalta Von Sperling (2007), alguns desses organismos podem ser patogênicos e capazes de provocar danos à saúde de seres humanos e animais. $\mathrm{O}$ autor acrescenta que os principais micro-organismos que oferecem riscos à saúde pública são bactérias, vírus, protozoários e helmintos, sendo o homem o principal responsável pela contaminação dos esgotos por agentes patogênicos por meio dos dejetos.

Silva e Ueno (2008) atentam para a necessidade da manutenção da qualidade dos corpos d'água em padrões considerados seguros para a sociedade, já que o contato da água com dejetos pode torná-la um meio de transmissão de agentes patogênicos. De acordo com Andrade Filho e Silva (2008), devido às complicações de se constatar a presença de micro-organismos patogênicos de forma direta, é comum a identificação desses organismos por meio das bactérias que apresentam características similares. Von Sperling (2007) explica que a dificuldade de obtenção de resultados a partir de amostras diretas está relacionada às baixas concentrações finais dos agentes patogênicos após a diluição de efluentes em rios, o que inviabiliza a execução de exames em laboratórios.

Este estudo tem grande relevância na análise do comportamento de autodepuração de rios que recebem fontes poluidoras de lançamento pontual. Benfeitorias podem ser realizadas no sistema de gestão da qualidade dos recursos hídricos ao utilizar modelos matemáticos como o de Streeter-Phelps. A grande vantagem desse modelo é que a entrada de dados é simples e os resultados são satisfatórios para diagnosticar os impactos causados em cursos d'água, bem como para controlar a entrada de fontes poluidoras, o que pode tornar viável a concessão de outorga para lançamento de efluentes e facilitar a fiscalização desse recurso. Modelos como o de Streeter-Phelps podem ser uma boa alternativa para casos com poucos dados para análises, tendo como exemplo as situações dos rios do estado do Ceará.

\section{Metodologia}

Este estudo trata da análise dos parâmetros de concentração de DBO e de coliformes termotolerantes para a avaliação da qualidade da água do rio Piranhas-Açu, localizado no estado do Rio Grande do Norte. Para tanto, foi aplicado o modelo 
de Streeter-Phelps simplificado, utilizando dados observados do rio, como vazão e velocidade, somados às simulações de lançamentos de efluentes para diferentes concentrações de poluentes.

Foram estabelecidos cenários de análise no intuito de demonstrar o comportamento desses parâmetros em relação aos padrões de qualidade da água doce estabelecidos pelas resoluções do CONAMA n n 357/2005 e 274/2005, além da comparação desses critérios para as vazões máximas e mínimas em épocas de cheias e secas, respectivamente.

Este estudo poderá auxiliar na tomada de decisão de profissionais que atuam nas áreas de saneamento ambiental e recursos hídricos, bem como viabilizar estudos de implantação de novos projetos e melhorias relacionadas ao custobenefício no tratamento de esgotos.

\subsection{Formulação do modelo}

Nesta pesquisa, serão considerados como variáveis de controle a demanda bioquímica de oxigênio (DBO) e os coliformes termotolerantes (CTT) presentes no corpo hídrico. As equações que analisam o comportamento desses valores são dadas do seguinte modo:

\subsubsection{Demanda bioquímica de oxigênio}

$$
\frac{\mathrm{dL}}{\mathrm{dt}}=-\mathrm{Kd} \cdot \mathrm{L}
$$

$\mathrm{L}=$ Concentração de DBO de remanescente $[\mathrm{mg} / \mathrm{L}]$;

$\mathrm{t}=$ Tempo [dia];

$\mathrm{Kd}=$ Coeficiente de remoção de DBO efetiva do rio.

\subsubsection{Coliformes termotolerantes}

$$
\frac{\mathrm{dN}}{\mathrm{dt}}=-\mathrm{Kb} \cdot \mathrm{N}
$$

N = Número de coliformes (org/100 mL, ou NMP - Número Mais Provável - por $100 \mathrm{~mL}$ );

$\mathrm{t}=$ Tempo [dia];

$\mathrm{Kb}=$ Coeficiente de decaimento bacteriano $\left[\mathrm{dia}^{-1}\right]$.

\subsection{Solução do modelo considerando apenas uma fonte poluidora pontual}

As equações a seguir apresentam as soluções do modelo matemático, Sperling (2007):

\subsubsection{Demanda bioquímica de oxigênio}

$$
\mathrm{L}=\mathrm{L}_{0} \cdot \mathrm{e}^{-\mathrm{Kd} \cdot \frac{x}{V_{0}}}
$$

$\mathrm{x}=$ Distância percorrida $[\mathrm{m}]$;

Vo $=$ Velocidade do rio, a montante do lançamento $[\mathrm{m} / \mathrm{dia}]$.

De acordo com Sperling (2007), a temperatura influencia substancialmente o valor do coeficiente de remoção da DBO já que interfere no metabolismo dos organismos decompositores. O autor apresenta a relação empírica entre a temperatura e o coeficiente analisado, sendo ela:

$\mathrm{Kd} \mathrm{T}=\mathrm{Kd} 20 \cdot \theta(\mathrm{T}-20)$

$\mathrm{KdT}=\mathrm{Kd}$ a uma temperatura $\mathrm{T}$ qualquer $\left[\mathrm{dia}^{-1}\right]$

$\mathrm{Kd} 20=\mathrm{Kd}$ a uma temperatura $\mathrm{T}=20^{\circ} \mathrm{C}\left[\mathrm{dia}^{-1}\right]$;

$\theta=$ Coeficiente de temperatura, com valor usual 1,047;

$\mathrm{T}=$ Temperatura do líquido $\left[{ }^{\circ} \mathrm{C}\right]$. 


\subsubsection{Coliformes termotolerantes}

$$
\mathrm{N}=\mathrm{No} \cdot \mathrm{e}^{-\mathrm{Kb} \frac{x}{V_{0}}}
$$

Sperling (2007) demonstra a variação do coeficiente de decaimento dos micro-organismos em função da temperatura de acordo com a formulação abaixo:

$\mathrm{KbT}=\mathrm{Kb} 20 \cdot \theta(\mathrm{T}-20)$

$\mathrm{KbT}=\mathrm{Kb}$ a uma temperatura $\mathrm{T}$ qualquer $\left[\mathrm{dia}^{-1}\right]$

$\mathrm{Kb} 20=\mathrm{Kb}$ a uma temperatura $\mathrm{T}=20^{\circ} \mathrm{C}\left[\mathrm{dia}^{-1}\right]$;

$\theta=$ Coeficiente de temperatura, com valor usual 1,07;

$\mathrm{T}=$ Temperatura do líquido $\left[{ }^{\circ} \mathrm{C}\right]$.

\subsubsection{Equação da mistura}

$$
\begin{aligned}
& \mathrm{No}=\frac{\mathrm{Qr} \cdot \mathrm{Nr}+\mathrm{Qe} \cdot \mathrm{Ne}}{\mathrm{Qr}+\mathrm{Qe}} \\
& \mathrm{Lo}_{0}=\frac{\mathrm{Qr} \cdot \mathrm{Lr}+\mathrm{Qe} \cdot \mathrm{Le}}{\mathrm{Qr}+\mathrm{Qe}}
\end{aligned}
$$

No = Concentração de coliformes na mistura esgoto-rio [NMP/100mL];

$\mathrm{Nr}=$ Concentração de coliformes no rio, a montante do lançamento [NMP/100mL];

$\mathrm{Ne}=$ Concentração de coliformes nos esgotos $[\mathrm{NMP} / 100 \mathrm{~mL}]$;

Lo = Concentração de DBO na mistura esgoto-rio $[\mathrm{mg} / \mathrm{L}]$;

$\mathrm{Lr}=$ Concentração de DBO no rio, a montante do lançamento $[\mathrm{mg} / \mathrm{L}]$;

$\mathrm{Le}=$ Concentração de DBO nos esgotos $[\mathrm{mg} / \mathrm{L}] ;$

Qr = Vazão do rio a montante do lançamento $\left[\mathrm{m}^{3} / \mathrm{s}\right]$;

Qe $=$ Vazão dos esgotos $\left[\mathrm{m}^{3} / \mathrm{s}\right]$.

\subsection{Caracterização da região}

No relatório realizado pela Agência Nacional de Águas - ANA (2014) são apresentados os seguintes dados sobre a bacia hidrográfica do rio Piranhas-Açu:

A bacia hidrográfica do rio Piranhas-Açu ocupa a maior área da região hidrográfica Atlântico Nordeste Oriental com 60\% pertencente ao Estado da Paraíba e 40\% ao Estado do Rio Grande do Norte. A nascente está situada no município de Bonito de Santa Fé, e seu fluxo d'água percorre os dois estados da bacia hidrográfica pelo rio chamado Piranhas, passando por importantes cidades do Rio Grande do Norte como Caicó e Assú, e finalmente desemboca no Oceano Atlântico em uma região posicionada próxima à cidade de Macau. Ao transpor a barragem Armando Ribeiro Gonçalves, o rio passa a ser conhecido como Piranhas-Açu.

O trecho do rio analisado está situado nas UPH's (Unidades de Planejamento Hidrológico) Médio Piranhas Potiguar e Bacias Difusas do Baixo Piranhas.

\subsection{Dados para as simulações}

Os dados do rio Piranhas-Açu foram fornecidos pela Secretaria dos Recursos Hídricos do Rio Grande do Norte no programa de monitoramento e fiscalização. Três seções do rio foram definidas com base no monitoramento de pontos realizado no dia 20 de agosto de 2002, com os seguintes dados: localização dos pontos, vazões, áreas e velocidades. As distâncias entre os pontos foram estabelecidas com o uso do programa AutoCad baseadas em escalas adquiridas com o programa Google Earth.

$\mathrm{Na}$ análise do decaimento da DBO foi considerado um lançamento pontual de efluente localizado na seção 1 com a vazão de $0,10 \mathrm{~m}^{3} / \mathrm{s}$. As concentrações da fonte pontual lançada no rio variaram entre $100 \mathrm{mg} / \mathrm{L}$ e $500 \mathrm{mg} / \mathrm{L}$, enquanto, as concentrações do rio à montante do ponto de lançamento, o rio foi considerado com uma carga de $2 \mathrm{mg} / \mathrm{L}$. Foi 
estabelecido o valor 0,50 dia $^{-1}$ para $\mathrm{K}_{\mathrm{d}}$ de acordo com Von Sperling (2007), posto que em todas as seções monitoradas o rio apresenta profundidade com menos de 1 metro, sendo considerado, portanto, como rio raso. De acordo com a Equação 4 , o valor do coeficiente foi alterado, considerando a temperatura do rio de $26^{\circ} \mathrm{C}$; e, consequentemente, a taxa de remoção foi elevada para $0,659 \mathrm{dia}^{-1}$.

$\mathrm{Na}$ verificação da redução dos coliformes termotolerantes foi considerado novamente um lançamento pontual localizado na seção $1 \mathrm{com}$ a vazão de $0,10 \mathrm{~m} 3 / \mathrm{s}$. Os valores das concentrações de coliformes foram estimados após tratamentos com eficiências variando entre $70 \%$ e $99 \%$ relativos a uma carga de esgoto bruto de $1,5 \times 10^{6}$ de organismos a cada $100 \mathrm{~mL}$, ao passo que o rio foi considerado limpo com carga de 10 organismos a cada $100 \mathrm{~mL}$. Foi assumido o valor típico de 1,00 dia ${ }^{-1}$ para o coeficiente de decaimento bacteriano e, após a aplicação da Equação 6, que altera o coeficiente em função da temperatura empregada, foi elevado o valor do coeficiente para 1,50 $\mathrm{dia}^{-1}$, considerando uma temperatura de $26^{\circ} \mathrm{C}$.

A Tabela 1 informa as concentrações de poluentes após a mistura.

Tabela1: Concentrações de poluentes após a mistura.

\begin{tabular}{c|c|c|c}
\hline \multicolumn{2}{c}{ DBO $(\mathrm{mg} / \mathrm{L})$} & \multicolumn{2}{c}{ CTT $(\mathrm{NMP} / 100 \mathrm{~mL})$} \\
\hline Efluente & Mistura & Efluente & Mistura \\
100 & 2,974 & $1,50 \times 10^{4}$ & 160 \\
200 & 3,969 & $7,50 \times 10^{4}$ & 756 \\
300 & 4,963 & $2,25 \times 10^{5}$ & 2248 \\
400 & 5,957 & $3,75 \times 10^{5}$ & 3739 \\
500 & 6,952 & $4,50 \times 10^{5}$ & 4485 \\
\hline
\end{tabular}

Nota: NMP - Número Mais Provável.

\subsection{Cenários de análise}

Nas simulações dos cenários foram feitas comparações entre diferentes padrões de qualidade da água doce segundo resoluções do CONAMA e variadas as cargas poluidoras nos lançamentos de efluentes.

\subsubsection{Cenário 1}

Neste cenário, foi analisado o decaimento da DBO e coliformes termotolerantes para diferentes concentrações de poluentes, levando em consideração as vazões monitoradas nos três pontos em estudo.

\subsubsection{Cenário 2}

Neste cenário, faz-se uma comparação das concentrações encontradas no cenário $1 \mathrm{com}$ os padrões de qualidade estabelecidos pelo CONAMA, para as diferentes classes de água doce.

\subsubsection{Cenário 3}

Neste cenário, são verificadas as vazões mais favoráveis e desfavoráveis da região para decaimento das concentrações dos poluentes. Chagas (2005) desenvolveu um estudo para o rio Potengi, próximo do rio Piranhas-Açu, que possui características semelhantes, em que foram adotadas vazões máximas e mínimas com valores de $14,5 \mathrm{~m}^{3} / \mathrm{s}$ e $2,6 \mathrm{~m}^{3} / \mathrm{s}$, respectivamente. Por esse motivo, também foram adotados estes valores de vazões máximas e mínimas no estudo.

As áreas das seções para vazões máximas foram consideradas a partir do cálculo da média das áreas monitoradas, enquanto que as áreas para vazões mínimas foram estipuladas de acordo com um cálculo baseado na proporção entre os valores de $14,5 \mathrm{~m}^{3} / \mathrm{s}, 2,6 \mathrm{~m}^{3} / \mathrm{s}$ e área máxima. Dessa maneira, as respectivas áreas são $16,50 \mathrm{~m}^{2}$ e 2,96 m².

\section{Resultados e Discussões}

Utilizando o modelo simplificado de Streeter-Phelps, foi possível fazer o estudo dos cenários apresentados anteriormente. Com as simulações dos cenários 1 e 2 pode-se verificar o comportamento das concentrações de DBO e de CTT nos trechos estabelecidos do rio, e analisar seu enquadramento, seguindo os padrões de qualidade da água nas 
resoluções do CONAMA, para as variadas concentrações. Com isto, pode-se fazer a análise da qualidade da água de forma simples.

Concentrações altas de DBO, por exemplo, indicam que grandes quantidades de oxigênio dissolvido serão consumidas por micro-organismos para a sintetização da matéria orgânica, o que acarreta a redução da quantidade disponível de oxigênio no meio aquático e, consequentemente, a mortandade de organismos aeróbios. E altas concentrações de coliformes termotolerantes que, embora não sejam patogênicos ao homem na sua maioria, indicam que há risco de contaminação da água por micro-organismos patogênicos, já que são geralmente originadas das fezes de animais de sangue quente.

\subsection{Cenário 1}

O cenário 1 apresenta o decaimento das concentrações de poluentes no percurso do rio para os diferentes lançamentos de cargas poluidoras na seção de lançamento. A Figura 1 ilustra o comportamento da DBO quando lançadas as fontes poluidoras, e a Figura 2 ilustra o comportamento do CTT.

Nas Figuras 1 e 2, é possível observar que, para uma mesma vazão de mistura, cargas mais elevadas de poluentes lançadas demandam maior tempo e distância para a diminuição das concentrações de DBO e CTT.

Figura 1: Comportamento da DBO.

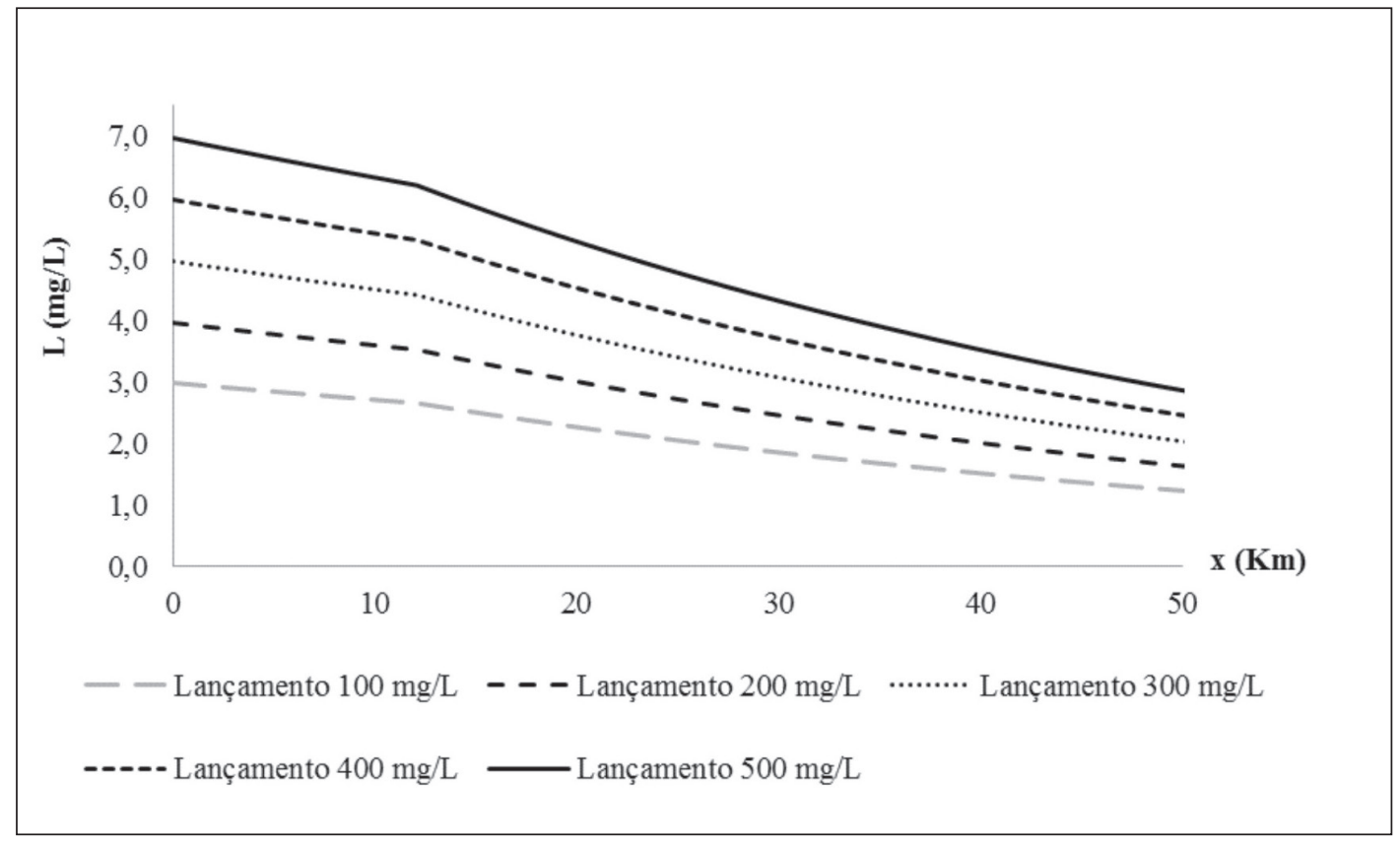

Verifica-se também, nas Figuras 1 e 2, a influência da velocidade no comportamento exponencial dos gráficos. Isso pode ser visto no trecho a aproximadamente $12 \mathrm{~km}$, quando é feita uma alteração na seção transversal, alterando a velocidade do rio nas seções posteriores. 
Figura 2: Comportamento de CTT.

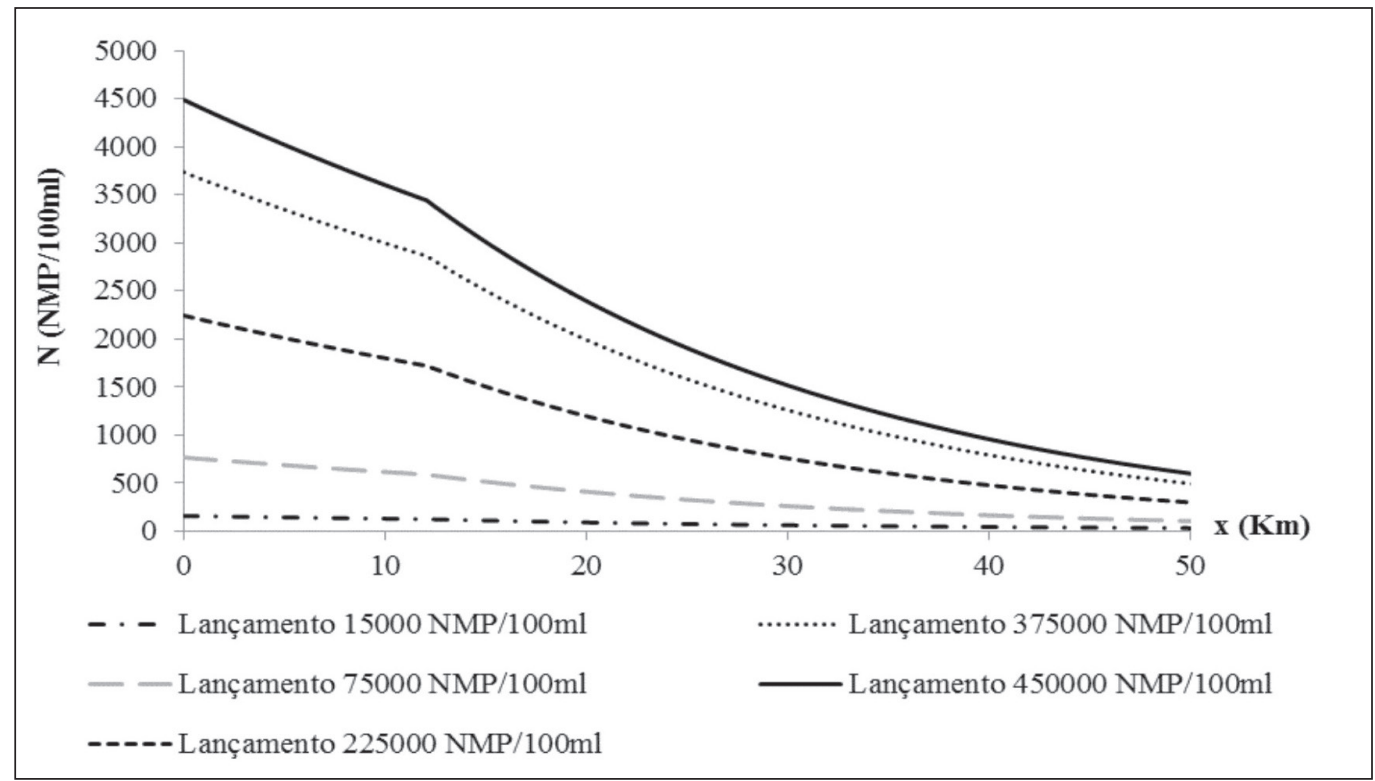

\subsubsection{Cenário 2}

No cenário 2, faz-se uma análise comparativa entre os limites das concentrações de DBO e de CTT estipulados pelo CONAMA e as concentrações das cargas simuladas nos lançamentos.

Figura 3: Análise DBO para a Classe I.

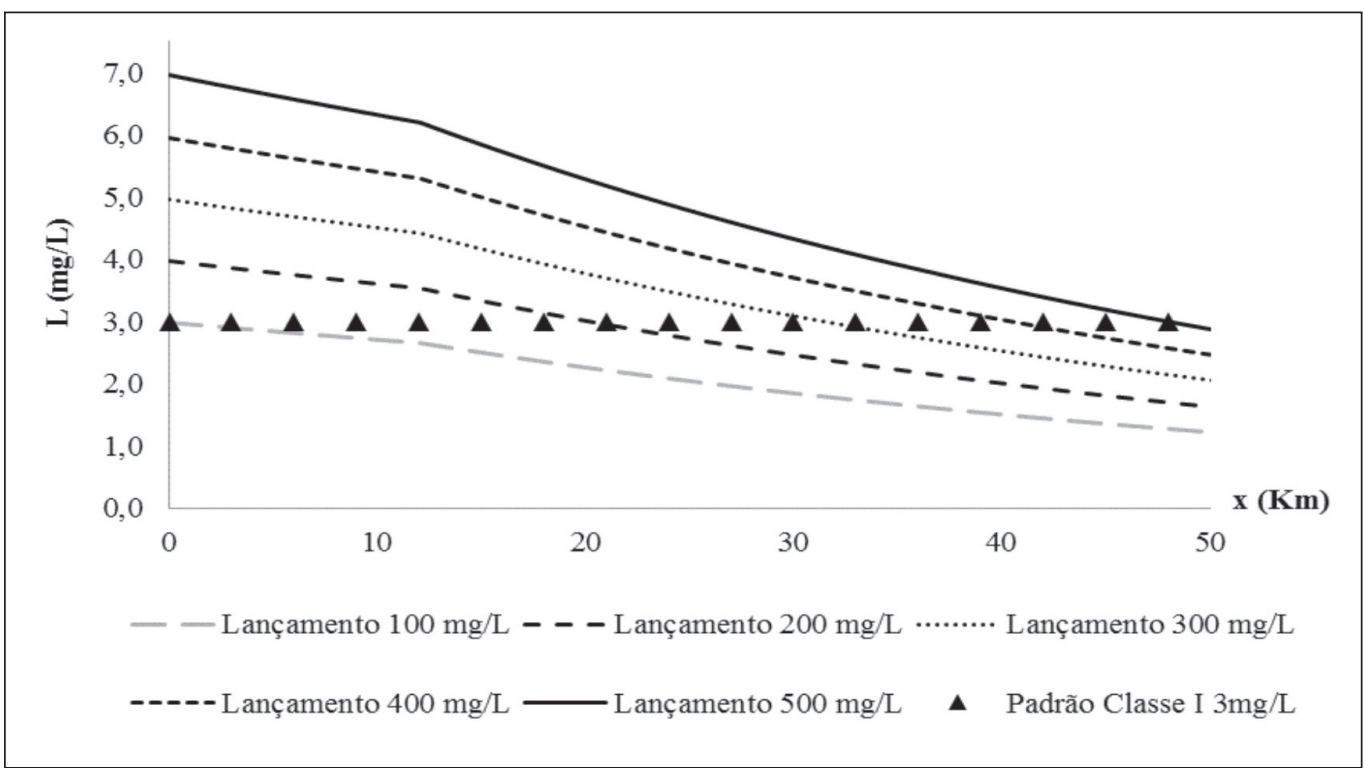

Observa-se na Figura 3, para a classe I do CONAMA, cujo limite de DBO é de $3 \mathrm{mg} / \mathrm{L}$, que apenas o lançamento de $100 \mathrm{mg} / \mathrm{L}$ está dentro dos padrões de qualidade. A classe II admite uma concentração máxima de $5 \mathrm{mg} / \mathrm{L}$ para DBO e, portanto, como ilustra a Figura 4, a referida classe apresenta condições em desacordo com o Conselho Nacional do Meio Ambiente para as simulações com efluentes que apresentem concentrações acima de $400 \mathrm{mg} / \mathrm{L}$. Todas as simulações estão de acordo com os critérios da resolução para a classe III, a qual especifica concentrações máximas de 10 mg/L (Figura 5). 
Figura 4: Análise DBO para a classe II.

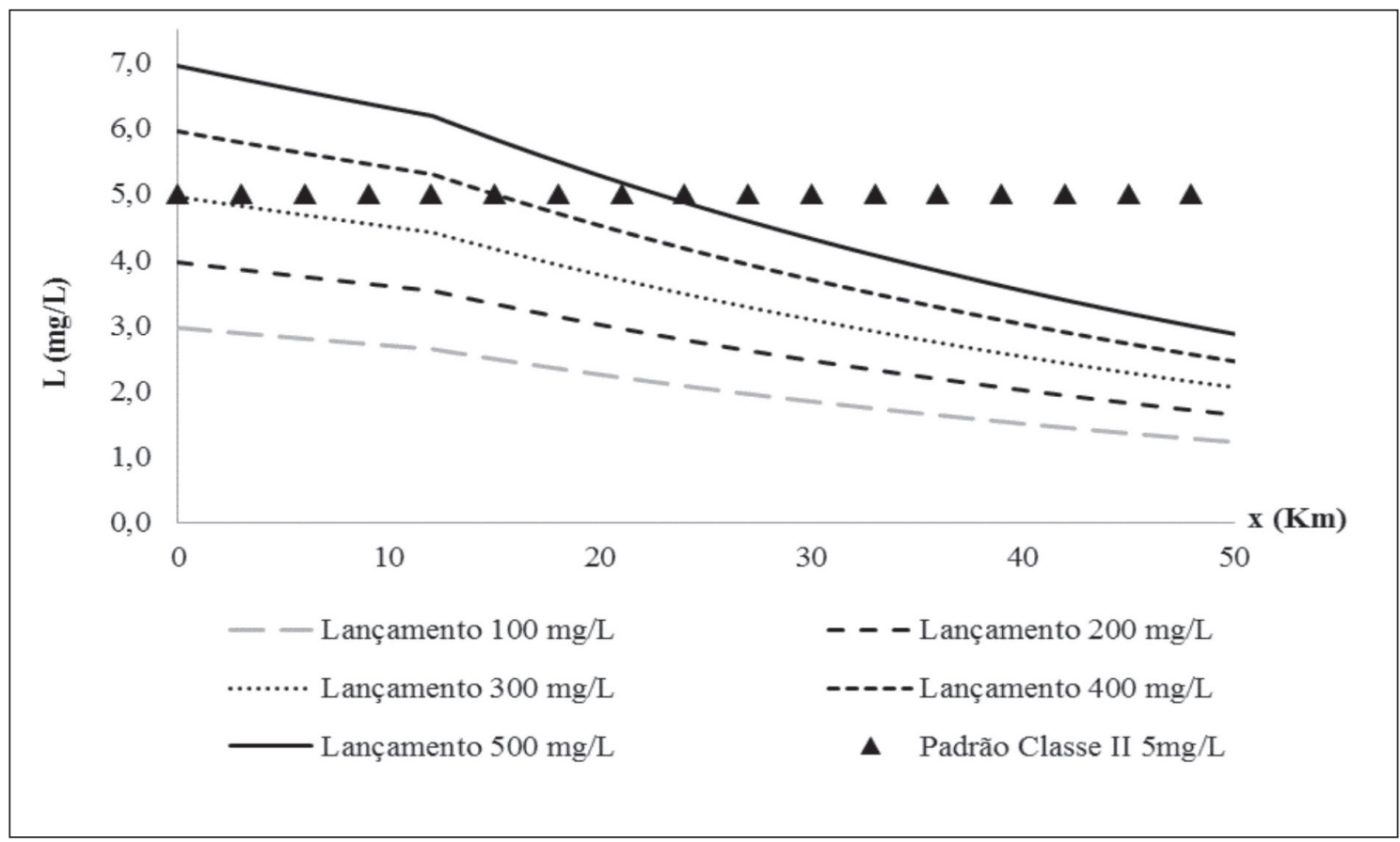

Figura 5: Análise DBO para a classe III.

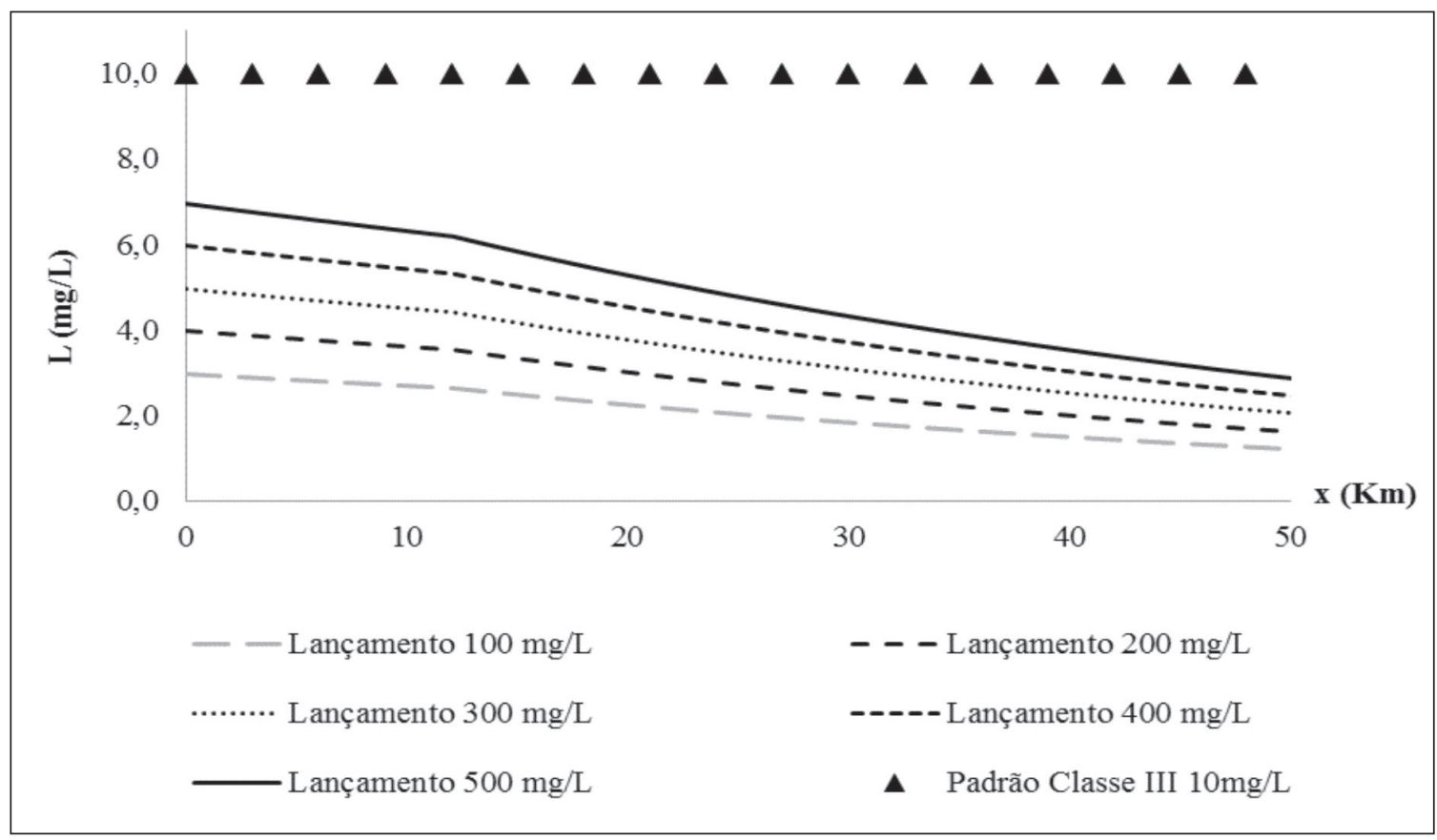

A Figura 6 apresenta diferentes critérios avaliados quanto à contaminação microbiológica. Para o lançamento com $1,50 \times 10^{4} \mathrm{NMP}$, o rio é considerado excelente para recreação de contato primário e o único dentro dos padrões para a classe I para os demais usos. Nas situações de lançamento com 7,50 x $10^{4} \mathrm{NMP}$, o rio é visto como satisfatório para recreação de contato primário e impróprio para os demais usos. 
Figura 6: Análise CTT para a classe I.

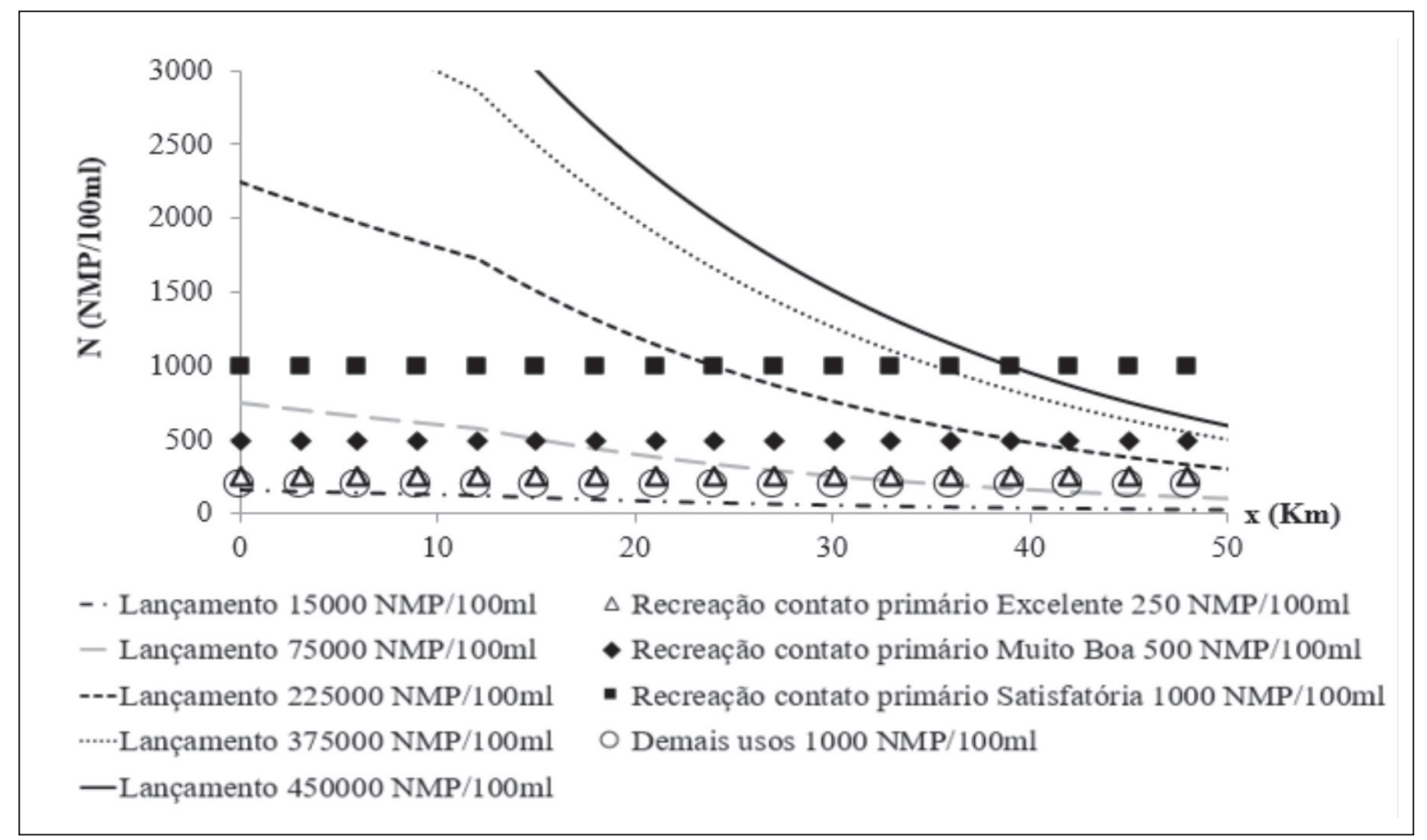

$\mathrm{Na}$ análise de coliformes termotolerantes relacionados à classe II (Figura 7), os lançamentos com cargas microbiológicas de 1,50 x 104 NMP e 7,50 x 104 NMP estão dentro dos padrões para os demais usos; porém, ao levarmos em consideração os limites estipulados para a recreação de contato primário, que são natação, esqui aquático e mergulho, são considerados de qualidade excelente e muito boa, respectivamente. Os rios que recebem as outras concentrações de carga poluidora são avaliados como impróprios pela resolução 274 do CONAMA.

Figura 7: Análise CTT para a classe II.

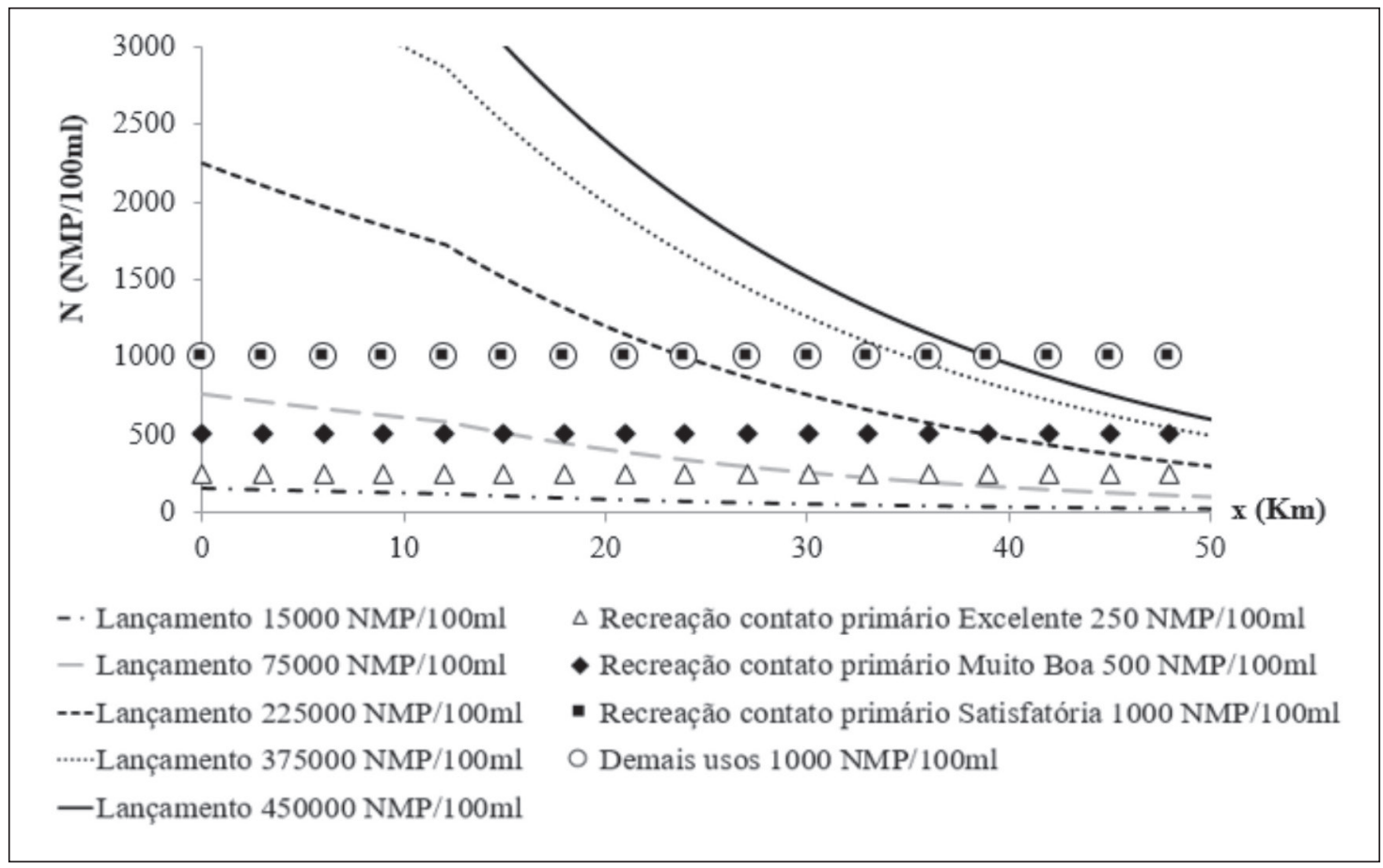


Já para a classe III (Figura 8), para lançamentos com 1,50 x 104 NMP, 7,50 x $10^{4}$ NMP e 2,25 x $10^{5}$ NMP, o rio está em conformidade com os limites para contato secundário; entretanto, apenas os dois primeiros são considerados aptos para dessedentação de animais criados em confinamento. Para os demais usos, apenas o efluente com 4,50 x $10^{5}$ NMP torna o rio inutilizável para tais finalidades.

Figura 8: Análise CTT para a classe III.

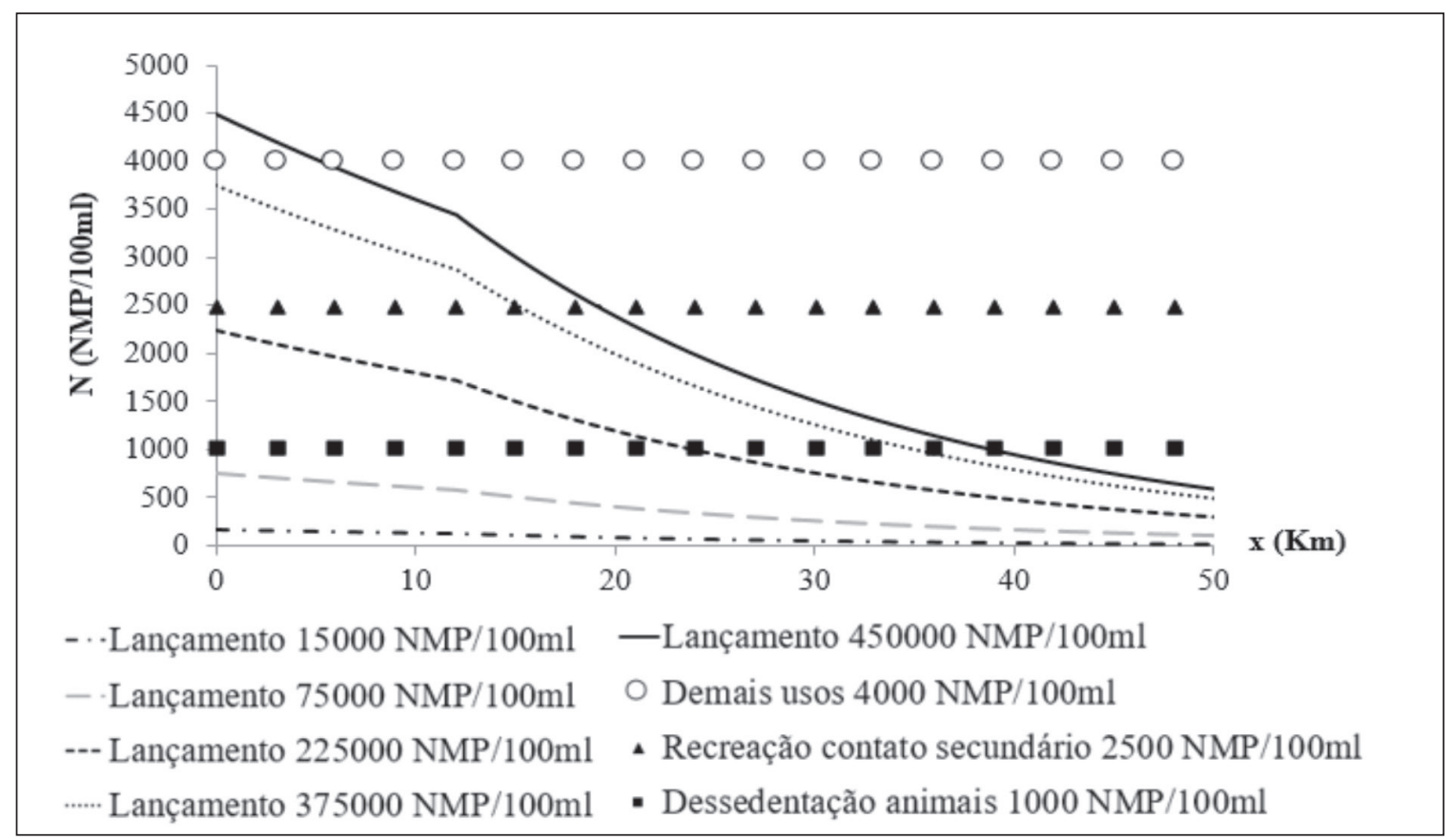

\subsubsection{Cenário 3}

Observa-se no resumo do Plano de Recursos Hídricos da Bacia Hidrográfica do Rio Piranhas-Açu que os rios da bacia ainda não foram enquadrados em classes. O artigo 42 da resolução 357 do CONAMA determina que um rio deve ser considerado de classe II quando o enquadramento não tenha sido aprovado. Portanto, foi considerado nesta pesquisa o rio Piranhas-Açu como classe II.

Figura 9: Análise DBO com vazão máxima para classe II.

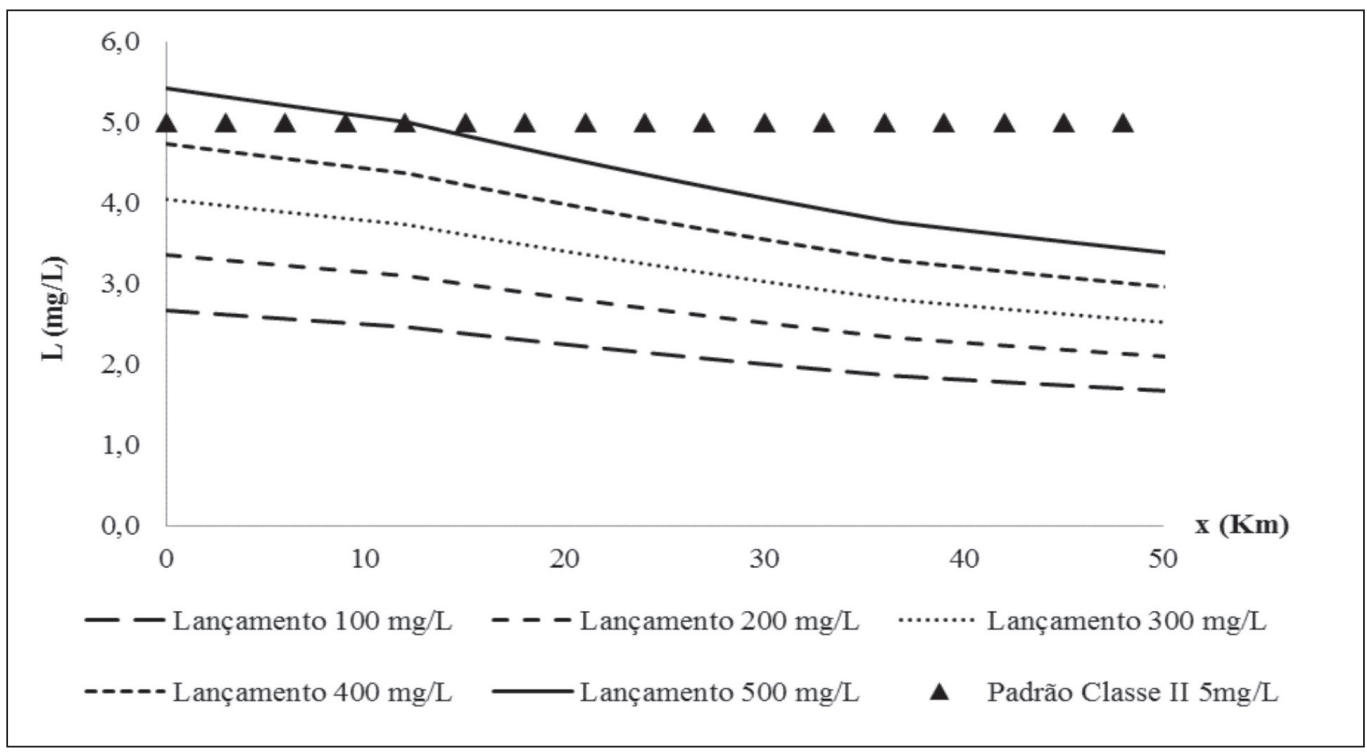


Figura 10: Análise DBO com vazão mínima para classe II.

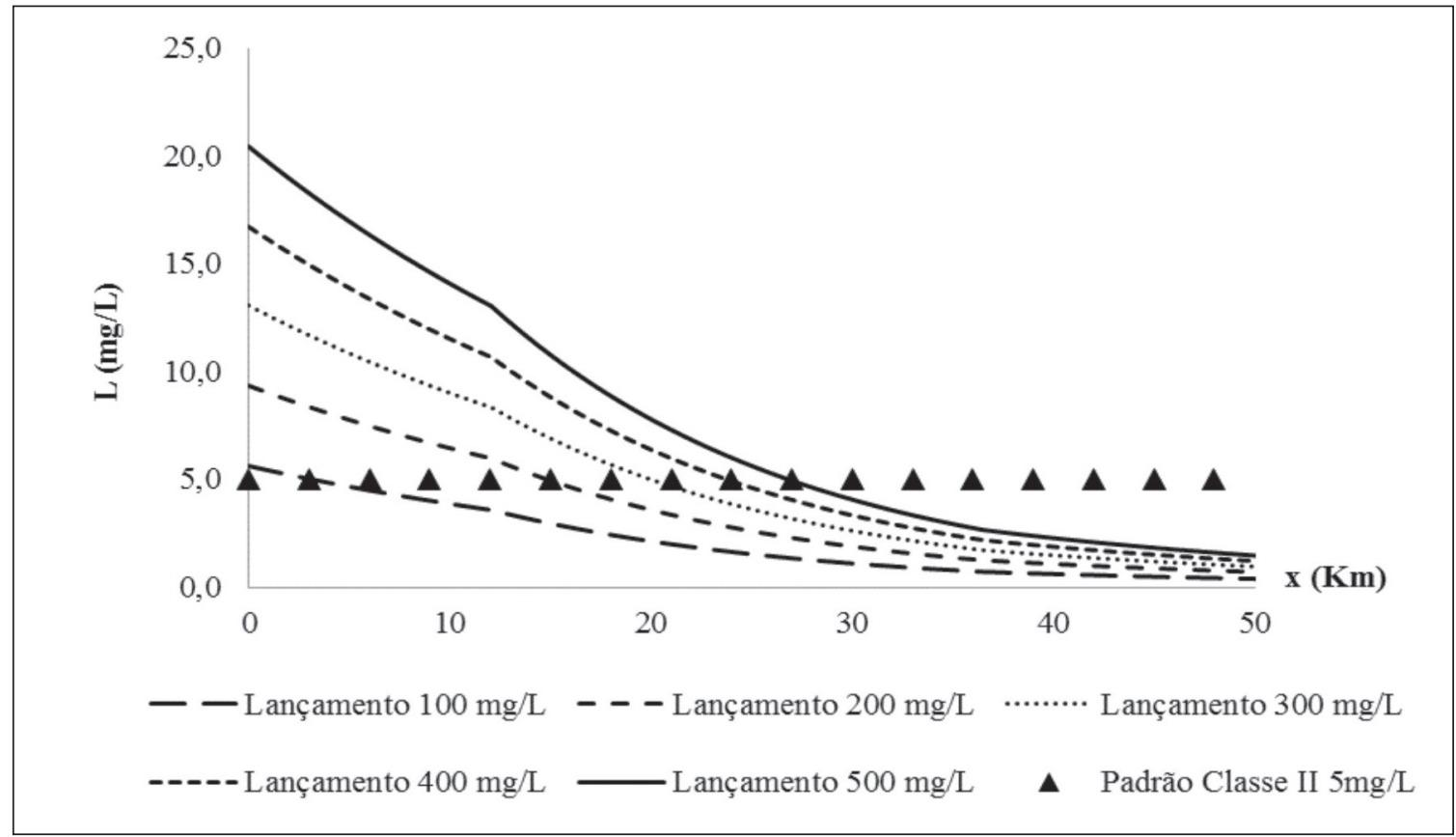

A Figura 11 apresenta o perfil das concentrações de coliformes termotolerantes para vazões mais favoráveis. Observa-se que os lançamentos com 1,50 x 104 NMP e 7,50 x 104 NMP são os únicos dentro dos padrões da classe para os demais usos; porém, ao ser avaliado o critério de recreação de contato primário, são considerados de qualidade excelente e satisfatória na devida ordem. As demais cargas lançadas são consideradas impróprias para recreação de contato primário.

Figura 11: Análise CTT com vazão máxima para classe II.

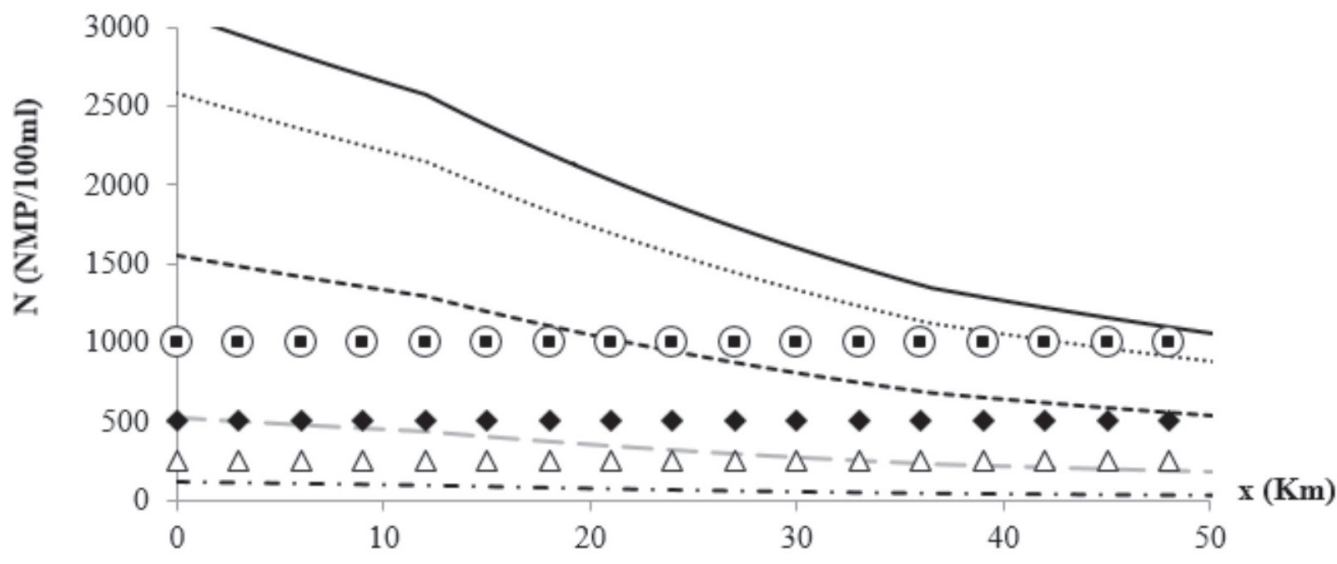

- - Lançamento $15000 \mathrm{NMP} / 100 \mathrm{ml}$

- Lançamento $75000 \mathrm{NMP} / 100 \mathrm{ml}$

---Lançamento $225000 \mathrm{NMP} / 100 \mathrm{ml}$

....... Lançamento $375000 \mathrm{NMP} / 100 \mathrm{ml}$

—Lançamento $450000 \mathrm{NMP} / 100 \mathrm{ml}$
$\Delta$ Recreação contato primário Excelente $250 \mathrm{NMP} / 100 \mathrm{ml}$

- Recreação contato primário Muito Boa 500 NMP/100ml

- Recreação contato primário Satisfatória 1000 NMP/100ml

O Demais usos $1000 \mathrm{NMP} / 100 \mathrm{ml}$ 

Sales

No caso da avaliação do número mais provável de micro-organismos biológicos para a vazão mais desfavorável (Figura 12), 1,50 x 104 NMP é a única carga que permite o rio considerado próprio para recreação de contato primário, sendo classificado satisfatório para esse fim. O referido lançamento também é o único que apresenta padrões, segundo a resolução, dentro dos demais usos após a mistura.

Figura 12: Análise CTT com vazão mínima para classe II.

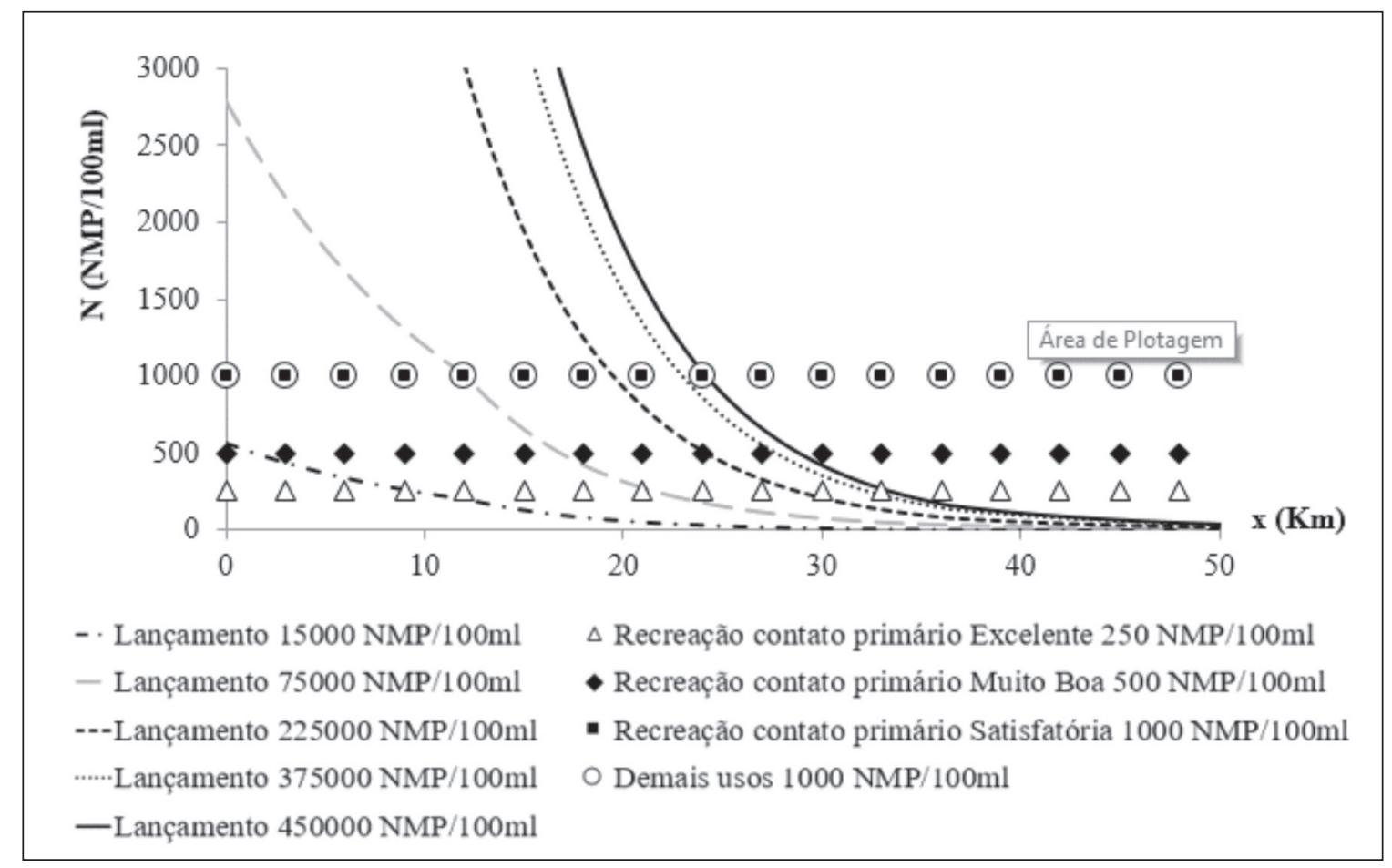

\section{Conclusões e recomendações}

A partir desta pesquisa, foi possível estabelecer, de forma simples, critérios de avaliação da qualidade da água, facilitando a tomada de decisão por parte de gestores ambientais.

Quanto aos resultados, registrou-se que, para maiores vazões do rio e menores concentrações do efluente, os corpos d'água conseguem diluir as cargas poluentes de forma mais eficiente, o que permite maiores possibilidades de lançamento segundo a legislação vigente. Isso fica evidenciado quando analisamos os resultados do cenário 3 , em que há numerosas restrições para lançamentos de efluentes no rio, enquadrado como classe II, quando usamos vazão de $2,6 \mathrm{~m} / \mathrm{s}$ em relação à vazão de $14,5 \mathrm{~m}^{3} / \mathrm{s}$. Para períodos de estiagem, em que as vazões reduzidas dos rios são comuns, o monitoramento desses recursos hídricos deve ser realizado de forma mais rigorosa, já que há uma maior probabilidade da presença de poluentes em altas concentrações.

Este estudo tem grande relevância na análise do comportamento de autodepuração de rios que recebem fontes poluidoras de lançamento pontual. Benfeitorias podem ser realizadas no sistema de gestão da qualidade dos recursos hídricos ao utilizar modelos matemáticos como o modelo simplificado de Streeter-Phelps. A grande vantagem desse modelo é que a entrada de dados é simples e os resultados são satisfatórios para diagnosticar os impactos causados em cursos d'água, bem como para controlar a entrada de fontes poluidoras, o que pode tornar viável a concessão de outorga para lançamento de efluentes e facilitar a fiscalização dos corpos hídricos. Modelos como o de Streeter-Phelps podem ser uma boa alternativa para casos com poucos dados para análises, tendo como exemplo as situações dos rios do Estado do Ceará. 


\section{Referências}

ANA. Agência Nacional de Águas. Plano de recursos hídricos da bacia hidrográfica do rio Piranhas-Açu. Brasília: ANA, 2014. Disponível em: < http://piranhasacu.ana.gov.br/produtos/sinteseDiagnostico.pdf $>$. Acesso em: 13 nov. 2015.

ANDRADE FILHO, F. M.; SILVA, L. M. Avaliação das concentrações de coliformes no afluente e efluente da ETE de Goiânia em 2007. 2008. 13 f. TCC (Graduação), Universidade Católica de Goiás, Goiânia, 2008. Disponível em: <http://www.ucg.br/ucg/prope/cpgss/ArquivosUpload/36/file/AVALIAÇÃO DAS CONCENTRAÇÕES DE COLIFORMES NO AFLUENTE E EFLUENTE DA ETE GOIÂNIA EM 2007.pdf`. Acesso em: 22 nov. 2015.

ANDRADE, L. N. Autodepuração dos corpos d'água. Revista da Biologia, São Paulo, v. 5, n. 2, p.16-19, dez. 2010.

AZEVEDO, L. G. T. et al. Sistemas de suporte à decisão para outorga de direitos de uso da água no Brasil: uma análise da situação brasileira em alguns estados. Bahia Análise e Dados, Salvador, v. 13, n esp. p.481-496, 2003. Disponível em: <http://www.bvsde.paho.org/bvsacd/cd17/suportdec.pdf >. Acesso em: 10 nov. 2015.

BEZERRA, I. S. O.; FRISCHKORN, H.; MENDONÇA, L. A. R. Autodepuração de cursos d'água: um programa de modelagem Streeter Phelps com calibração automática e correção de anaerobiose. Revista Escola de Minas, Ouro Preto, v. 61, n. 2, p.249-255, abr. 2008. Disponível em: <http://www.scielo.br/pdf/rem/v61n2/a20v61n2.pdf >. Acesso em: 15 nov. 2015.

BOANO, F.; REVELLI, R.; RIDOLFI, L. Stochastic modelling of DO and BOD components in a stream with random inputs. Advances in Water Resources, Turin, v. 29, n. 9, p.1341-1350, set. 2006.

BRAGA, B. et al. Introdução à engenharia ambiental: o desafio do desenvolvimento sustentável. 2. ed. São Paulo: Pearson Prentice Hall, 2005.

BRASIL. Lei no ${ }^{\circ}$ 9.433, em 8 de janeiro de 1997. Institui a Política Nacional de Recursos Hídricos, cria o Sistema Nacional de Gerenciamento de Recursos Hídricos, regulamenta o inciso XIX do art. 21 da Constituição Federal, e altera o art. $1^{\circ}$ da Lei $n^{\circ} .8 .001$, de 13 de março de 1990, que modificou a Lei $n^{\circ} .7 .990$, de 28 de dezembro de 1989. Diário Oficial da República Federativa do Brasil, Brasília, DF, 9 de janeiro de 1997. Não paginado. Disponível em: < http://www.planalto.gov.br/ccivil_03/LEIS/L9433.htm>. Acesso em: 10 nov. 2015.

. Ministério do Meio Ambiente - MMA. Plano nacional de recursos hídricos: prioridades 2012-

2015. Brasília: SRHU, 2011. Disponível em: <http://www.mma.gov.br/estruturas/161/_publicacao/161_ publicacao16032012065259.pdf > . Acesso em: 2 set. 2015.

. Resolução $\mathrm{n}^{\circ} .357$, de 17 de março de 2005. Dispõe sobre a classificação dos corpos de água e diretrizes ambientais para o seu enquadramento, bem como estabelece as condições e padrões de lançamento de efluentes, e dá outras providências. Diário Oficial da União, Brasília, DF, 18 de março de 2005. Disponível em: < http://www.mma. gov.br/port/conama/legiabre.cfm?codlegi=459>. Acesso em: 11 nov. 2015.

. Resolução ${ }^{\circ} 274$, de 29 de novembro de 2000. Define os critérios de balneabilidade em águas brasileiras.

Diário Oficial da União, Brasília, DF, 25 de janeiro de 2001. Disponível em: < http://www.mma.gov.br/port/conama/ legiabre.cfm?codlegi=272>. Acesso em: 13 nov. 2015.

CÂNDIDO, A.; SANTOS, S. $\mathrm{H}_{2} \mathrm{O}$ o o símbolo da vida. AbasteCE, Fortaleza, v. 2, n. 6, p. 8-11, abr.jun. 2000.

CHAGAS, P. F. Perspectivas da aplicação da teoria fuzzy para cálculo de risco em sistemas hidrodinâmicos. 2005. 189 f. Tese (Doutorado), Universidade Federal do Ceará, Fortaleza, 2005.

CHANDRA, R. et al. Renosterveld conservation in South Africa: a case study for handling uncertainty in knowledgebased neural networks for environmental management. Journal of Environmental Informatics, Cape Town, v. 13, n. 1, p.56-65, mar. 2009.

COX, B. A. A review of currently available in-stream water-quality models and their applicability for simulating dissolved oxygen in lowland rivers. Science of The Total Environment, Reading, n. 314-316, p.335-377, out. 2003.

CRUZ, J. C. Disponibilidade hídrica para outorga: avaliação de aspectos técnicos e conceituais. 2001. 189 f. Tese (Doutorado), Universidade do Rio Grande do Sul, Porto Alegre, 2001. Disponível em: <http://www.lume.ufrgs.br/ bitstream/handle/10183/2602/000323130.pdf>. Acesso em: 22 nov. 2015.

FITZPATRICK, J. J. Assessing skill of estuarine and coastal eutrophication models for water quality managers. Journal of Marine Systems, Mahwah, v. 76, n. 1-2, pp.195-211, fev. 2009. 
LI, J. et al. An integrated fuzzy-stochastic modeling approach for risk assessment of groundwater contamination. Journal of Environmental Management, Columbia, v. 82, n. 2, p.173-188, jan. 2007.

MACRIS, V. Cobrança pelo uso da água. AbasteCE, Fortaleza, v. 2, n. 6, p.13-14, abr./jun. 2000.

MANNINA, G.; VIVIANI, G. Water quality modelling for ephemeral rivers: Model development and parameter assessment. Journal of Hydrology, v. 393, n. 3-4, p.186-196, nov. 2010.

MELO, M. C. Avaliação e proposição de critérios de outorga para lançamento de efluentes em corpos d’água. 2006. 120 f. Dissertação (Mestrado), Universidade Federal de Minas Gerais, Belo Horizonte, 2006. Disponível em: <http://www.bibliotecadigital.ufmg.br/dspace/bitstream/handle/1843/ENGD-6TLNLZ/214m.pdf?sequence=1>. Acesso em: 23 nov. 2015.

SALES, R. J. de M.; ARAÚJO, J. A. F. de; SANTOS, S. H. Aplicação das equações de Streeter-Phelps em rios que recebem fontes de poluentes pontuais e difusas, para avaliar o comportamento das concentrações de oxigênio dissolvido. Periódico Eletrônico Fórum Ambiental da Alta Paulista, [S.1.], v. 10, n. 12, nov. 2014. ISSN 1980-0827. Disponível em: <http://www.amigosdanatureza.org.br/publicacoes/index.php/forum_ambiental/article/view/908>. Acesso em: 20 nov. 2015.

SILVA, A. B. A.; UENO, M. Qualidade sanitária das águas do Rio Una, São Paulo, Brasil, no período das chuvas. Revista Biociências, Taubaté, v. 14, n. 1, p.82-86, jan/jul. 2008. Disponível em: <http://periodicos.unitau.br/ ojs-2.2/index.php/biociencias/article/viewFile/487/284>. Acesso em: 4 out. 2015.

SILVEIRA, A.; TELES, R. B. Autodepuração de escoamentos naturais de água Estudo de caso: de modelagem matemática em um trecho do Ribeirão Preto, Ribeirão Preto-SP. In: XXX CONGRESO INTERAMERICANO DE INGENIERÍA SANITARIA Y AMBIENTAL, 2006, Ribeirão Preto. Anais... . Punta del Este: Aidis, 2006. p. 1 - 10. Disponível em: <http://www.bvsde.paho.org/bvsaidis/uruguay30/BR08489_Teles.pdf $>$. Acesso em: 22 nov. 2015.

VON SPERLING, M. Estudos e modelagem da qualidade da água de rios. 1. ed. Belo Horizonte: UFMG, 2007.

Sobre os autores

\section{Roani Simões Veras}

Engenheiro Civil, Universidade de Fortaleza - UNIFOR.

Ingrid Fernandes de Oliveira Alencar

Estudante de Engenharia Civil, Universidade de Fortaleza - UNIFOR.

Victor Prisco Diogo de Holanda

Engenheiro Civil, Universidade de Fortaleza - UNIFOR.

Thainá Rayanne Soares

Estudante de Engenharia Civil, Universidade de Fortaleza - UNIFOR.

\section{Raquel Jucá de Moraes Sales}

Tecnóloga em Saneamento Ambiental - Instituto Federal de Educação, Ciência e Tecnologia do Ceará, M.Sc e Doutora em Engenharia Civil - Recursos Hídricos - Universidade Federal do Ceará.

Professora Auxiliar do Centro de Ciências Tecnológicas da Universidade de Fortaleza. 